\title{
TRAVIS - a free analyzer and visualizer for Monte Carlo and molecular dynamics trajectories
}

\author{
Martin Brehm*, Barbara Kirchner \\ From 7th German Conference on Chemoinformatics: 25 CIC-Workshop \\ Goslar, Germany. 6-8 November 2011
}

We present TRAVIS ("TRajectory Analyzer and VISualizer"), a free program package for analyzing and visualizing Monte Carlo and molecular dynamics trajectories [1]. The aim of TRAVIS is to collect as many analyses as possible in one program, creating a powerful tool and making it unnecessary to use many different programs for evaluating simulations. This should greatly rationalize and simplify the workflow of analyzing trajectories. TRAVIS is written in $\mathrm{C}++$, open-source freeware and licensed under the terms of the GNU General Public License (GPLv3). It is easy to install (platform independent, no external libraries) and easy to use. On this poster, we present some of the algorithms that are implemented in TRAVIS - many of them widely known for a long time, but some of them also to appear in literature for the first time. All shown analyses only require a standard MD trajectory as input data.

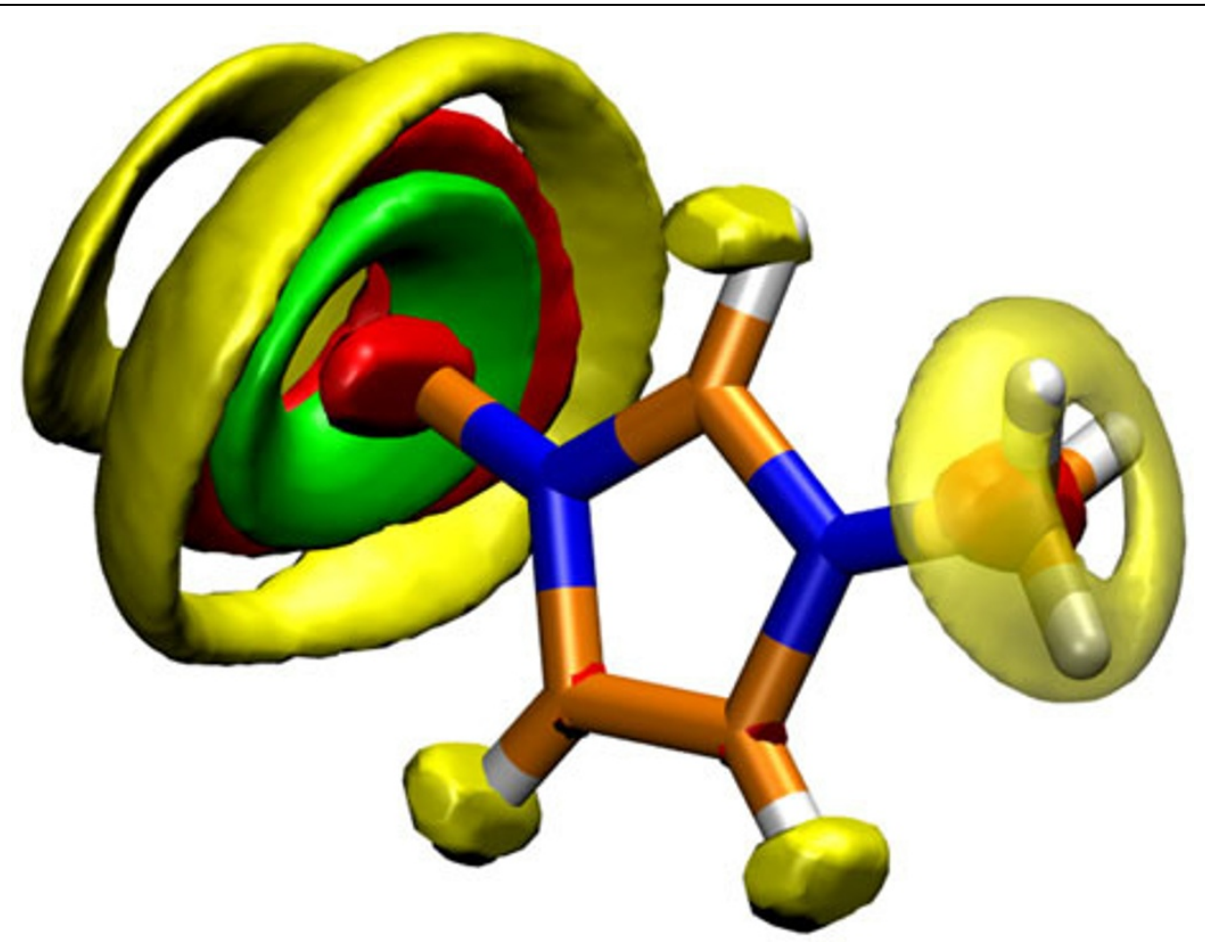

Figure 1

Wilhelm-Ostwald-Institut für Physikalische und Theoretische Chemie, Universität Leipzig, Leipzig, Germany 


\section{Reference}

1. Brehm M, Kirchner B: TRAVIS - A free Analyzer and Visualizer for Monte Carlo and Molecular Dynamics Trajectories. J Chem Inf Model 2011, 51:2007-2023, doi:10.1021/ci200217w.

doi:10.1186/1758-2946-4-S1-F1

Cite this article as: Brehm and Kirchner: TRAVIS - a free analyzer and

visualizer for Monte Carlo and molecular dynamics trajectories. Journal of Cheminformatics 2012 4(Suppl 1):F1.

\section{Publish with ChemistryCentral and every scientist can read your work free of charge}

"Open access provides opportunities to our colleagues in other parts of the globe, by allowing anyone to view the content free of charge."

W. Jeffery Hurst, The Hershey Company.

- available free of charge to the entire scientific community

- peer reviewed and published immediately upon acceptance

- cited in PubMed and archived on PubMed Central

- yours - you keep the copyright

Submit your manuscript here:

http://www.chemistrycentral.com/manuscript/<smiles>c1ccccc1</smiles> 